\title{
Developmental exposure to the A6-pesticide causes changes in tyrosine hydroxylase gene expression, neurochemistry, and locomotor behavior in larval zebrafish
}

NASRI Ahmed ( $\square$ a7mednas@gmail.com )

University of Carthage Faculty of Sciences of Bizerte: Universite de Carthage Faculte des Sciences de Bizerte https://orcid.org/0000-0002-0144-5154

Lafon Pierre-André

University of Montpellier: Universite de Montpellier

Amine Mezni

Taif University College of Science

Philippe Clair

University of Montpellier: Universite de Montpellier

Nicolas Cubedo

University of Montpellier: Universite de Montpellier

Ezzeddine Mahmoudi

University of Carthage Faculty of Sciences of Bizerte: Universite de Carthage Faculte des Sciences de Bizerte

Hamouda Beyrem

University of Carthage: Universite de Carthage

Mireille Rossel

University of Montpellier: Universite de Montpellier

Véronique Perrier

University of Montpellier: Universite de Montpellier

\section{Research Article}

Keywords: zebrafish exposure, malformations, A6 accumulation, tyrosine hydroxylase, locomotion behavior

Posted Date: September 13th, 2021

DOI: https://doi.org/10.21203/rs.3.rs-891214/v1 
License: (c) (i) This work is licensed under a Creative Commons Attribution 4.0 International License. Read Full License 


\section{Abstract}

In recent years, the increase in the synthesis of biopesticides for alternative agricultural uses has necessitated the study of their impacts. Among these compounds, several of them are known to exert endocrine-disrupting effects causing deregulation of a variety of physiological functions affecting cell signaling pathways involved in neural cell differentiation leading to developmental neurotoxicity. In this current paper, we thus determined the impact of the biopesticide A6 on zebrafish larvae, which is structurally linked to estrogenic endocrine disruptors. The objective of this study was to define the toxicity of $A 6$, the mechanisms responsible, and to evaluate its effects on the locomotor activity at nanomolar concentrations $(0,0.5,5$, and $50 \mathrm{nM})$. We show through its blue fluorescence properties that $A 6$ accumulates in different parts of the body as intestine, adipose tissue, muscle, yolk sac and head. We display also that A6 disrupt the development and affects the function of the central nervous system, especially the expression of tyrosine hydroxylase $(\mathrm{TH})$ in dopaminergic neurons. We studied whether A6 disturbs the target genes expression and recorded that it downregulated genes embroiled in $\mathrm{TH}$ expression, suggesting that A6's neurotoxic effect may be the result of its binding propinquity to the estrogen receptor.

\section{Introduction}

The exponential growth of the world's population has necessitated the use of intensive production systems in agriculture globally [1]. The over the top use of synthetic pesticides and improve crop yields places great strain on natural resources [2]. The use of chemical pesticides has led to the appearance of several impacts in the environment, including toxic effects on non-target organism [3]. The arrival of new technologies such as high throughput screening and mass spectrometry in the 1990 s boosted "green" chemistry, i.e., the identification of new molecules extracted from plants, and the production of derived molecules with improved properties [4]. This "green" chemistry aims to design industrial processes that are more respectful of the environment and to generate products that are more harmless to non-target organisms [5]. These pesticides of plant origin or biopesticides are currently being explored as promising alternatives to synthetic pesticides [4], because they are considered less harmful to non-target organisms since they are of natural origin [6]. A6 is a biopesticide derived from the molecule a-terthienyl which was originally isolated from plants such as Asteraceae [7] for its blue fluorescent properties [8,9], as well as being described to have herbicidal activity [10].

The use of biological origin pesticides in agriculture presents more and more a risk due to their gradual accumulation in aquatic environments [11]. In addition, an increasing number of these compounds are now considered endocrine disruptors (EDCs) $[12,13]$. Estrogenic EDCs act by modulating the interaction between 17ß-estradiol (E2) and estrogen receptors (ER) that dysregulate physiological function [14]. Nasri et al. showed that $A 6$ exercised anti-estrogenic activity and down-regulat cell proliferation in zebrafish brain after decrease of gene transcription of estrogen receptors (ER) [9]. It has been demonstrated also that a-terthienyl has the capacity to inhibit several enzymes such as superoxide dismutase (SOD) and acetylcholinesterase (AChE) both in vitro and in vivo leading to important consequences in mosquito 
larvae nervous system [7]. New data have shown that $A 6$ at $5 \mathrm{mg} / \mathrm{kg}$ accelerates the prion pathology in mice after treatment [15]. Generally, biopesticides classified as endocrine disruptors (EDCs) have shown harmful effects on the nervous system development in aquatic organisms [16]. Neurotoxicity caused by these environmental pollutants is responsible for changes in locomotor behavior and an alteration in the regulation of the dopaminergic systems $[17,18]$.

Tyrosine hydroxylase is used as biomarker dopaminergic neurons since it is a dopamine synthesis enzyme $[19,20]$. Dopamine is considered is a neurohormone and neurotransmitter that plays a crucial role in regulating animal life by acting in both the central and peripheral nervous systems [21]. Dopamine in the peripheral nervous system has been reported in the kidneys, carotid bodies, peripheral arteries, and parts of the gastrointestinal, genitourinary, and endocrine systems [22]. The monoaminergic neurons use dopamine as a transmitter, and it contributes to a variety of functional processes in the vertebrates [23]. The very wide distribution of dopaminergic cells in the central nervous system illustrates its involvement in a varied range of central functions, such as motivation [24], learning and memory [25], affective and emotional processes [26], control of body temperature [27], locomotion [28], and behaviors [29].

Because the multiple advantages (small size, high fecundity, short life cycle, and facile breeding in the laboratory), zebrafish was used for behavioral and developmental studies [30], genetics research [31], and toxicology bioassays [32]. In our study, it was used to determine the acute toxicity of the biopesticide A6 at low concentrations. The aim was to evaluate the associated physical malformations, the body accumulation, and locomotion behavior as well as to determine the mechanism responsible in relation with the toxicity by evaluation the TH expression after exposure.

\section{Materials And Methods}

\subsection{Fish strains and embryos treatment}

The pyrimidino bithiophene or biopesticide A6 and Dimethyl sulfoxide (DMSO) were obtained from Maybridge [10]. Animals were treated in the laboratory Inserm U1198 following the National and European ethic guidelines under permit number (agreement \#A34-172-37). Fish were fed twice daily and handled according to standard procedures in the laboratory [33]. Adult fish were maintained at $28^{\circ} \mathrm{C}$, with a circadian rhythm ( $14 \mathrm{~h}$ of light and $10 \mathrm{~h}$ of darkness), in a recirculation, flow-through system where tank water is constantly filtered. Embryos were obtained from pair matings and exposed in groups in an incubator, which was staged according to a previously published method [34]. Embryos of wild-type $A B$ line were dechorionated at $24 \mathrm{hpf}$, and then kept in the incubator $\left(28^{\circ} \mathrm{C}\right)$ in six-well plates, with 10 to 20 embryos in two milliliters (per well) of solution for A6 tissue accumulation study, body malformations and locomotion behaviors, or in glass bottles, with 80 embryos in one hundred milliliters of solution for gene expression and immunochemical study. For all experiments, the A6 concentrations tested were 0.5 $\mathrm{nM}, 5 \mathrm{nM}$, and $50 \mathrm{nM}$ when compared to a DMSO control.

\subsection{Response of zebrafish larvae to the effects of $A 6$}


Embryos of wild-type $A B$ were treated with all concentrations of $A 6$ or to solvent control (DMSO) for 6 or 9 days. Morphological abnormalities were identified using a stereomicroscope (Olympus Corporation). Three separate experiments were effectuated and 10 larvae were used for each condition. Individual malformation was expressed as the percentage of embryos with at least one malformation, in comparison to the control.

\subsection{Measurement of A6 accumulation in tissues}

Tricaine was used for anesthetizing embryos of wild-type AB [9] and put on slides using agar, at the end of treatment to A6 or to control DMSO. Using confocal microscopy and ImageJ software, we were capable to follow fluorescence labeling in contaminated and un contaminated embryos and process the associated images. The number of zebrafish embryos observed for each condition was more than 10 for three distinct experimentations.

\subsection{Locomotor behavior measurement}

Behavioral swimming was conducted using an automated behavior recording system, Zebrabox (ViewPoint Life Science, France), after zebrafish larvae treatment to A6 or control DMSO. Wild-type embryos were placed individually in a monitoring area in Zebrabox mounted with a camera system and their free-swimming activities were continuously recorded for the succeeding ten minutes [9]. The swimming of more than $2 \mathrm{~mm}$ is represented by red lines; small movements $(0.5-2 \mathrm{~mm})$ are symbolized by green lines, and trips below $0.5 \mathrm{~mm}$ indicate inactivity. The number of animals followed for a given concentration was more than fifteen for three distinct experiments.

\subsection{Gene expression measurement by q-PCR}

Fertilized wild-type embryos were exposed from 1 to $6 \mathrm{dpf}$ with all concentrations of A6 or to control DMSO. Each experimental group consisted of 80 embryos treated in $100 \mathrm{ml}$ of solution. A set of sixty animal brains were used to extract total RNA using RNeasy Mini Kit (Qiagen, Courtaboeuf, France) [35]. Extracts were treated with RNase free DNase to purify the RNA from DNA contamination. Total RNA concentration was quantified using a nanodrop spectrophotometer, and quality was verified by measuring the $260 / 280 \mathrm{~nm}$ ratio (1.8-2.0) [9]. A Reverse-transcription followed by real-time PCR amplification was applied for mRNAs. The relative target genes transcription was performed with SYBR green detection, as previously described [9]. QRT-PCR was performed with six biological replicates (three technical replicates) using a LightCycler 480 Instrument and the protocol consisted of the following phases: denaturation of PCR reaction mixture at $95^{\circ} \mathrm{C}$ for $10 \mathrm{~min}$ followed by 45 cycles of amplification cycle profile (denaturation for $10 \mathrm{~s}$ at $95^{\circ} \mathrm{C}$; annealing for $10 \mathrm{~s}$ at $60^{\circ} \mathrm{C}$; and elongation for $10 \mathrm{~s}$ at $72^{\circ} \mathrm{C}$ ). Real-time detection of the SYBR green fluorescence effect (reflecting the amount of PCR produced) was determined at the end of each elongation part. Construction of standard curves using DNA standards was performed in order to display the consistency and efficiency of each qRT-PCR test. Expression of the target gene was quantified based on the comparative cycle threshold (Ct) method [9]. Normalized expression was calculated for quantification according to the $2-\Delta \Delta C T$ method [36] with the internal control gene, ef1a. Elongation factor 1 alpha (ef1a) was chosen as a reference [37] because of its 
stability during zebrafish development and after treatment to environmental pollutants [38]. For the amplification of cDNA, oligonucleotide primers were used as described in Table 1.

Table 1

Primers used for qRT-PCR analyses.

\begin{tabular}{|c|c|c|}
\hline Target genes & Accession numbers & Primer sequence \\
\hline \multirow[t]{2}{*}{ th1 } & \multirow[t]{2}{*}{ XM_682702.1 } & (fw) 5'-GAC-GGA-AGA-TGA-TCG-GAG-ACA-3' \\
\hline & & (rev) 5'-CCG-CCA-TGT-TCC-GAT-TTC-T-3' \\
\hline \multirow[t]{2}{*}{ th2 } & \multirow[t]{2}{*}{ NM_001001829 } & (Fw) 5'-CTCCAGAAGAGAATGCCACATG-3' \\
\hline & & (Rev) 5'-ACGTTCACTCTCCAGCTGAGTG-3' \\
\hline \multirow[t]{2}{*}{ ef1a } & \multirow[t]{2}{*}{ NM_131263.1 } & (fw) 5'-AGCAGCAGCTGAGGAGTGAT-3' \\
\hline & & (rev) 5'-CCGCATTTGTAGATCAGATGG-3' \\
\hline
\end{tabular}

\subsection{Immunolabelling TH}

After exposure to A6 or control DMSO for 6 days, zebrafish larvae were put in $4 \%$ paraformaldehyde (PFA) in phosphate-buffered saline (PBS) $+0.5 \%$ Triton at ambient temperature for $2.5 \mathrm{~h}$ with agitation and then washed with PBS. Then, the samples were fixed with PFA using Triton for $2 \mathrm{~h}$ for permeabilization, followed by blocking using a solution (PBS 1×/BSA 1x/DMSO 1x) and incubating with TH primary antibodies ( $\mathrm{TH}, 1: 500$, ThermoFisher \# PA1-4679) overnight at $4^{\circ} \mathrm{C}$ for immunofluorescence studies. The following day, the zebrafish were laved with PBST while changing the solution regularly (every 1-2 $\mathrm{h}$ ). Fluorescence-conjugated secondary antibody Alexa-488 (1/1000) was added to the primary antibody and left overnight (at $4^{\circ} \mathrm{C}$ ). The next morning, larvae were washed in PBST (at least four times for 30 min each), ideally all day. Hoechst dye (stock $7.5 \mathrm{mg} / \mathrm{ml} ; 1 / 1000$ ) was added after the last wash, followed by incubation for 40 min and then washing with PBST (three times).

\subsection{Imaging analysis and fluorescence quantification}

Zebrafish larvae were placed in depressed slides in a drop of agarose (1\%) and were immersed in system water and subjected to imaging using a water immersion objective from a confocal microscope (Leica, SPE). Stacks of images were processed and quantified with ImageJ (http://rsbweb.nih.gov/ij/). The nomenclature used for the brain nuclei and regions was in accordance with that of the zebrafish atlas [39].

\subsection{Data analysis}

When our data showed approximate normality, analysis of variance (1-ANOVA) was chosen for global search of differences, and Tukey's HSD test was eventually used to compare treatment effects of the biopesticide $A 6$ and control groups for evaluation of the malformation rate, swimming behavior, and gene expression. An a of 0.05 assesses the significance of differences for all measures. 


\section{Results}

\subsection{A6 caused morphological abnormalities in zebrafish larvae}

The treatment of embryos from $24 \mathrm{hpf}$ with the highest nanomolar concentration of A6 caused some abnormalities in zebrafish larvae, including yolk sac edema (YSE), spinal curvature (SC), tail deformity (TD), and pericardial edema (PE) (Fig. 1A). PE, TD, and SC were observed after 6 days, and YSE was detected only after 9 days of exposure at the same concentration (Fig. 1A). The total malformation rates in the group treated with $50 \mathrm{nM}$ A6 were $16.66 \%(p=0.0006)$ after 6 days and $36.66 \%(p<0.0002)$ after 9 days of experience (Fig. 1B).

\subsection{Measurement of tissus accumulation with $\mathrm{A} 6$}

We examined whether the biopesticide A6 might accumulate in the body of zebrafish larvae after 6 days of exposure at all of the considered concentrations. Zebrafish larvae were placed in depressed slides in a drop of agarose $(1 \%)$ and were immersed in system water, followed by imaging using a water immersion objective from a confocal microscope (Leica, SPE). The results showed that A6 accumulated in the intestine, adipose tissue, muscle, yolk sac and head based on its blue fluorescence and the ability to detect this by confocal microscopy, when compared with control DMSO (Fig. 2).

\subsection{A6 changed the locomotor behavior}

The results showed that A6 significantly altered the free-swimming distance of zebrafish larvae in the center and periphery at all concentrations. Figure 3 displays that the swimming behavior of zebrafish larvae was affected by treatment with all concentrations of A6. At the center, the duration of inactivity (distance less than $0.5 \mathrm{~mm}$ ), as well as the time spent for medium and long trips, was long. At the periphery, the idle time was short, as was the time spent moving medium and long distances.

\subsection{A6 downregulates gene expression}

The level of mRNA of each of the TH isoforms, th1 and th2, showed a clear dose-dependent decrease following exposure to the biopesticide A6. Exposure to A6 or to the control DMSO from $1 \mathrm{dpf}$ until $6 \mathrm{dpf}$ caused significant decreases in the mRNA level of th2 in the range of $0.3-(p=0.005), 0.32-(p=0.006)$ and 0.51- $(p=0.037)$ (Fig. 4B). In addition, the mRNA level of th1 was decreased in order 0.69- $(p=0.040)$ only with $50 \mathrm{nM}$ of $\mathrm{A6}$ (Fig. 4A). These results reveal that the biopesticide A6 could directly or indirectly disturb the synthesis of enzymes regulating dopamine synthesis in zebrafish following exposure to it.

\subsection{Imminochimistry $\mathrm{TH}$}


To confirm the locomotor disruption observed after treatment with the biopesticide, animals were treated to $\mathrm{A} 6$ or control DMSO. Changes in the patterning of their dopaminergic neurons were examined at $6 \mathrm{dpf}$. The nomenclature used for the dopaminergic neurons was as described previously [40]. Low doses of A6 resulted in appreciable changes of brain TH expression compared with that in the control (Fig. 5). The first changes in neuronal patterning were observed in the olfactory bulb (OB) at all concentrations tested, where labeling of these neurons showed a decrease in fluorescence intensity (Fig. 5B-D) in contrast to control (Fig. 5A). The subpallium within the telencephalon (SP) also appears not to be altered by $\mathrm{A6}$. In the pre-tectal $(\mathrm{Pr})$ area, the density of neuronal labeling was not affected (Fig. $5 \mathrm{~F}-\mathrm{H})$ compared with that in the control DMSO group (Fig. 5E). In addition, neuronal labeling in the area postrema (AP) showed a reduction with only the $50 \mathrm{nM}$ of $\mathrm{A6}$ (Fig. 5L) compared with the control (Fig. 5I).

\section{Discussion}

Our study investigated the deleterious effects of A6 on zebrafish larvae. The results showed that this biopesticide has adverse effects on neurodevelopment after its accumulation in the lateral line [9] in the organs (Fig. 2). It also has disturbed the expression of the key genes related to the control of neurodevelopment. The exposure of zebrafish larvae to A6 resulted in malformations only at $50 \mathrm{nM}$. Vismara et al. showed that the herbicides (paraquat and diquat) are highly embryotoxic and cause malformations in zebrafish larvae, primarily by causing lipid peroxidation [41]. Generally, pesticides act by affecting various visceral organs in a way that causes abnormalities in different parts of the corps [42, 43]. In addition to these morphological changes, exposure to pesticides at the embryonic and larval stages also results in decline hatching success and larval death [44] or behavioral modifications [45, 46]. These data are alike to those in our current study in which A6-treated embryos showed abnormal behaviors. Slotkin asserted that organophosphate pesticides cause developmental neurotoxicity and long-term cognitive and behavioral effects through routes including catecholaminergic mechanisms, as well as affecting cell signaling pathways involved in neural cell differentiation [47]. In our study, in the A6exposed groups, the locomotor behavior was disturbed. This may have been associated with the potential neurotoxicity of biopesticides (Fig. 3), which was in agreement with a previous article by [9], or related to nervous system alteration.

Generally, behavior is used as an index for evaluating neurodevelopment and has been appeared to be very sensitive to environmental pollutants early in life [48]. Exposure to members of the organophosphate pesticide family has been shown to alter swimming behavior [49] and the reply to a surprising excitation [50]. Several studies have also observed reduced locomotor movement in larval fish immediately following embryonic treatment to chlorpyrifos [51, 52]. In addition, exposure to the insecticide imidacloprid during the embryonic period was found to reduce the motion activity of zebrafish larvae [53]. Numerous analyses have displayed that various neurotransmitter systems and cellular functions are affected by exposure to organophosphate pesticides during the developmental period. A significant quantity of investigation has concentrated on recognizing the mechanisms by which pesticides apply their effects on normal behavioral development. However, exposure to organophosphates during development leads to transcriptional changes in genes linked to the action of the serotonin, dopamine, 
and norepinephrine neurotransmitter systems [54]. Several factors may contribute to altered behavior at low doses, such as a rise in dopamine release in synapses caused by stress [55] and a decrease in the uptake of dopamine by dopamine transporters [56]. The activity change may be due to dopamineinitiated modification in other nervous system pathways that regulate locomotion [57]. The appearance of behavioral defects after exposure to A6 could be linked to possible effects in the brain, mainly on neurotransmitters. These play a essential role in the nervous system development [58,59]. A number of studies have published that chemical pollutants might have adverse effects on zebrafish neurotransmitters $[60,61,62]$. In particular, the dopaminergic system is considered to consist of regulator neurotransmitters and is linked to behavior and nervous disorders [23].

Dopamine is a well-described neurotransmitter known for its initiating function of motor activity in the vertebrates' brain [63]. A variety of pesticide groups have been related with selective dopaminergic degeneration, including dithiocarbamates, and organochlorines [64, 65], many of which have been shown to induce a loss of dopaminergic neurons causing a parkinsonian syndrome $[66,67]$. Other studies have shown that neurobehavioral defects are associated with developmental exposure to chlorpyrifos and can change brain dopamine content $[68,69]$. Sallinen et al. showed that the pesticide MPTP (1-methyl-4phenyl-1,2,3,6-tetrahydropyridine) causes specific loss of dopaminergic neurons, decreases of the dopamine levels, and impaired motility in zebrafish larvae [70].

Changes in dopaminergic neuron and neurotransmitter levels were also found to be correlated with a locomotor phenotype in larval zebrafish described as a deficit in global swimming parameters [62]. In our study, the biopesticide A6 appeared to induce damage to dopamine neurons by initiating a Baxdependent apoptosis pathway and decreasing cell proliferation in the brain [9]. Wang et al. reported that the exposure of adult zebrafish to rotenone decreased the levels of dopamine and $\mathrm{TH}$, and caused alteration in motor function and behavior, as well as olfactory dysfunction [71]. Precedent studies indicated that dopaminergic neurons are susceptible to paraquat $[72,73]$ and a diminution of motor activity can results $[74,75]$.

Tyrosine hydroxylase is the first enzyme involved in the synthesis of catecholamines, especially dopamine [76]. It is the molecular marker most commonly used in teleosts as in mammals to evaluate the rate of biosynthesis of neurotransmitters by measuring TH enzymatic activity [77] or TH protein [78] or mRNA levels [79]. Our results showed that treatment of zebrafish embryos with A6 significantly decreased the mRNA level of th1 at only the highest concentration of $50 \mathrm{nM}$ and the level of th2 at all tested concentrations. In a preceding study, Brooks et al. showed that paraquat can diminish TH levels in the striatum in mice [80]. In addition, Reeves et al. measured TH levels in striatal sections of rat brains treated chronically with paraquat by both HPLC and immunohistochemistry and observed a decrease in TH in both analyses [81]. Many studies have related the exposure to chlorpyrifos to cell signaling perturbations affecting accordingly dopamine receptor signaling $[82,83,84]$. The decreased TH expression observed in our present report is possibly attached to the potential of the biopesticide $A 6$ to inhibit cell proliferation [9]. Additionally, A6 has the potential to cause endocrine disruption, being known to change the mRNA expression of estrogenic hormone-related genes such as esr1 and esr2a [9]. The involvement of 
estrogenic hormones in the regulation of TH expression has been suggested by several groups [85, 86 , 87]. This regulation takes place through the control of the transcription of the sensitive genes by nuclear receptors and may explain the TH expression identified in our work.

\section{Conclusions}

Our current results demonstrate that the exposure of zebrafish larvae to A6 led to a significant modification of the locomotion profile associated with the observation of neurological damage and a decrease in the expression of $\mathrm{TH}$. These changes recorded were generally correlate with the alteration of physiological hormonal functions $[7,88,89]$. These negative effects are triggered by disruption of estrogenic signaling pathways. Our results have just approved and added additional information on the impact of pesticides of plant origin on non-target species and highlight the importance of toxicological studies on the zebrafish model species.

\section{Declarations}

\section{Acknowledgments}

The authors extend their appreciation to INSERM (Institut National de la Santé et de la Recherche Médicale, France) for supporting several missions for Dr. Ahmed Nasri in Montpellier. We thank Elodie Jublanc and Vicky DIAKOU for help and training on SPE-confocal.

\section{Funding}

This work was funded by Taif University Research through Project number (TURSP-2020/28), Taif University, Taif, Saudi Arabia.

\section{Author information}

\section{Affiliations}

U1198 MMDN (Molecular Mechanisms of Neurodegenerative Diseases), Inserm (National Institute for Health and Medical Research), MGX (Montpellier GenomiX), BioCampus, University of Montpellier, 34095 Montpellier, France: Ahmed Nasri, Pierre-André Lafon, Philippe Clair, Nicolas Cubedo, Mireille Rossel, and Véronique Perrier

Laboratory of Environment Biomonitoring, Unit of coastal Ecology and Ecotoxicology, Faculty of Sciences of Bizerte, University of Carthage, 7021 Zarzouna, Tunisia: Ahmed Nasri, Ezzeddine Mahmoudi, Hamouda Beyrem

Department of Chemistry, College of Science, Taif University, P.O. Box 11099, Taif 21944, Saudi Arabia: Amine Mezni 
Corresponding author

Correspondence to Ahmed Nasri

\section{Ethics declarations}

Conflict of interest. The authors declare that they have no conflict of interest.

Ethical statements: This article was approved by INSERM and Montpellier University (agreement \#A34172-37, 10 April 2013).

\section{Authors' contributions}

Specific contributions made by each author are as follow:

- Conceptualization: Ahmed Nasri, Mireille Rossel, Véronique Perrier

- Methodology: Ahmed Nasri, Amine Mezni, Philippe Clair, Nicolas Cubedo, Mireille Rossel, Véronique

Perrier

- Analysis and interpretation: Ahmed Nasri, Pierre-André Lafon, Ezzeddine Mahmoudi, Hamouda Beyrem, Mireille Rossel, Véronique Perrier

- Writing original draft, review and revision: Ahmed Nasri, Amine Mezni, Mireille Rossel, Véronique Perrier All authors have read and agreed to the published version of the paper.

Availability of the data and material: Not applicable

Code availability: Not applicable

Consent to participate: Not applicable.

Consent for publication: Not applicable.

\section{References}

1. Köhler HR, Triebskorn R (2013) Wildlife ecotoxicology of pesticides: Can we track effects to the population level and beyond? Science (80)

2. Liu Y, Pan X, Li J (2014) A 1961-2010 record of fertilizer use, pesticide application and cereal yields: a review. Agron. Sustain. Dev

3. Abdelkhalek NKM, Ghazy EW, Abdel-Daim MM (2015) Pharmacodynamic interaction of Spirulina platensis and deltamethrin in freshwater fish Nile tilapia, Oreochromis niloticus: impact on lipid 
peroxidation and oxidative stress. Environ Sci Pollut Res. https://doi.org/10.1007/s11356-014-35780

4. Benelli G, Pavela R, Canale A, Mehlhorn H (2016) Tick repellents and acaricides of botanical origin: a green roadmap to control tick-borne diseases? Parasitol. Res

5. Campos EVR, de Oliveira JL, Pascoli M et al (2016) Neem oil and crop protection: From now to the future. Front. Plant Sci. 2016, 7, 1494

6. Shao H, Zhang Y (2017) Non-target effects on soil microbial parameters of the synthetic pesticide carbendazim with the biopesticides cantharidin and norcantharidin. Sci Rep. https://doi.org/10.1038/s41598-017-05923-8

7. Nivsarkar M, Cherian B, Padh H (2001) Alpha-terthienyl: A plant-derived new generation insecticide. Curr. Sci

8. Zechmeister L, Sease JW (1947) A Blue-Fluorescing Compound, Terthienyl, Isolated from Marigolds. J Am Chem Soc. https://doi.org/10.1021/ja01194a032

9. Nasri A, Valverde AJ, Roche DB et al (2016) Neurotoxicity of a biopesticide analog on Zebrafish larvae at nanomolar concentrations. Int J Mol Sci. https://doi.org/10.3390/ijms17122137

10. Friedman DCS, Friedman $P$ (1995) A theoretical study of 2,2';5',2"-terthiophene (a-T) and its analogs. Part 1. Correlation of electronic structure and energies with herbicidal phototoxicity. J Mol Struct THEOCHEM. https://doi.org/10.1016/0166-1280(94)03930-J

11. Tejada M, Morillo E, Gómez I et al (2017) Effect of controlled release formulations of diuron and alachlor herbicides on the biochemical activity of agricultural soils. J Hazard Mater. https://doi.org/10.1016/j.jhazmat.2016.10.002

12. Jiang J, Chen Y, Yu R et al (2016) Pretilachlor has the potential to induce endocrine disruption, oxidative stress, apoptosis and immunotoxicity during zebrafish embryo development. Environ Toxicol Pharmacol. https://doi.org/10.1016/j.etap.2016.01.006

13. Nasri A, Allouche M, Hannachi A et al (2021) Ecotoxicity of polybrominated diphenyl ether (BDE-47) on a meiobenthic community with special emphasis on nematodes: Taxonomic and trophic diversity assessment. Environ Pollut 277:116727. https://doi.org/10.1016/j.envpol.2021.116727

14. Sonnenschein C, Soto AM (1998) An updated review of environmental estrogen and androgen mimics and antagonists. In: Journal of Steroid Biochemistry and Molecular Biology

15. Lafon P-A, Imberdis T, Wang Y et al (2018) Low doses of bioherbicide favour prion aggregation and propagation in vivo. Sci Reports 201881 8:1-14. https://doi.org/10.1038/s41598-018-25966-9

16. Legradi JB, Di Paolo C, Kraak MHS et al (2018) An ecotoxicological view on neurotoxicity assessment. Environ. Sci. Eur

17. Paiva IM, Sartori BM, Castro TFD et al (2020) Behavioral plasticity and gene regulation in the brain during an intermittent ethanol exposure in adult zebrafish population. Pharmacol Biochem Behav. https://doi.org/10.1016/j.pbb.2020.172909 
18. Xin N, Jiang Y, Liu S et al (2020) Effects of prednisolone on behavior and hypothalamic-pituitaryinterrenal axis activity in zebrafish. Environ Toxicol Pharmacol.

https://doi.org/10.1016/j.etap.2020.103325

19. Hokfelt T, Johansson O, Fuxe K et al (1976) Immunohistochemical studies on the localization and distribution of monoamine neuron systems in the rat brain. I. Tyrosine hydroxylase in the mes- and diencephalon. Med Biol

20. Pickel VM, Joh TH, Reis DJ (2006) Ultrastructural localization of tyrosine hydroxylase in noradrenergic neurons of brain. Proc Natl Acad Sci. https://doi.org/10.1073/pnas.72.2.659

21. Ugrumov MV, Saifetyarova JY, Lavrentieva AV, Sapronova AY (2012) Developing brain as an endocrine organ: Secretion of dopamine. Mol Cell Endocrinol.

https://doi.org/10.1016/j.mce.2011.07.038

22. Pivonello R, Ferone D, Lombardi $\mathrm{G}$ et al (2007) Novel insights in dopamine receptor physiology. Eur $\mathrm{J}$ Endocrinol. https://doi.org/10.1530/eje.1.02353

23. Zagrean L (2014) Principles of Neural Science. Acta Endocrinol. https://doi.org/10.4183/aeb.2014.529

24. Schultz W (2002) Getting formal with dopamine and reward. Neuron; Neuron, 36(2), 241-263

25. Goldman-Rakic PS (1997) The Cortical Dopamine System: Role in Memory and Cognition. Adv Pharmacol. https://doi.org/10.1016/S1054-3589(08)60846-7

26. Diehl DJ, Gershon S (1992) The role of dopamine in mood disorders. Compr Psychiatry. https://doi.org/10.1016/0010-440X(92)90007-D

27. Cox B, Kerwin R, Lee TF (1978) Dopamine receptors in the central thermoregulatory pathways of the rat. J Physiol. https://doi.org/10.1113/jphysiol.1978.sp012476

28. Mok EYM, Munro AD (1998) Effects of dopaminergic drugs on locomotor activity in teleost fish of the genus Oreochromis (Cichlidae): Involvement of the telencephalon. Physiol Behav. https://doi.org/10.1016/S0031-9384(98)00038-9

29. Dufour S, Sebert ME, Weltzien FA et al (2010) Neuroendocrine control by dopamine of teleost reproduction. J. Fish Biol

30. Grunwald DJ, Eisen JS (2002) Headwaters of the zebrafish - emergence of a new model vertebrate. Nat. Rev. Genet

31. Eisen JS (1996) Zebrafish make a big splash. Cell 87:969-977. https://doi.org/10.1016/S00928674(00)81792-4

32. Hill RL, Janz DM (2003) Developmental estrogenic exposure in zebrafish (Danio rerio): I. Effects on sex ratio and breeding success. Aquat Toxicol 63:417-429. https://doi.org/10.1016/S0166$445 \times(02) 00207-2$

33. Westerfield M (2007) The Zebrafish Book. A Guide for the Laboratory Use of Zebrafish (Danio rerio), 5th Edition. Univ Oregon Press Eugene 
34. Nasri A, Mezni A, Lafon PA et al (2021) Ethinylestradiol (EE2) residues from birth control pills impair nervous system development and swimming behavior of zebrafish larvae. Sci Total Environ 770:145272. https://doi.org/10.1016/j.scitotenv.2021.145272

35. Diotel N, Servili A, Gueguen MM et al (2011) Nuclear progesterone receptors are up-regulated by estrogens in neurons and radial glial progenitors in the brain of zebrafish. PLoS One. https://doi.org/10.1371/journal.pone.0028375

36. Schmittgen TD, Livak KJ (2008) Analyzing real-time PCR data by the comparative CT method. Nat Protoc. https://doi.org/10.1038/nprot.2008.73

37. McCurley AT, Callard GV (2008) Characterization of housekeeping genes in zebrafish: Male-female differences and effects of tissue type, developmental stage and chemical treatment. BMC Mol Biol. https://doi.org/10.1186/1471-2199-9-102

38. Tang R, Dodd A, Lai D et al (2007) Validation of zebrafish (Danio rerio) reference genes for quantitative real-time RT-PCR normalization. Acta Biochim Biophys Sin (Shanghai). https://doi.org/10.1111/j.1745-7270.2007.00283.x

39. Rink E, Wullimann MF (2002) Development of the catecholaminergic system in the early zebrafish brain: An immunohistochemical study. Dev Brain Res. https://doi.org/10.1016/S01653806(02)00354-1

40. Tay TL, Ronneberger O, Ryu S et al (2011) Comprehensive catecholaminergic projectome analysis reveals single-neuron integration of zebrafish ascending and descending dopaminergic systems. Nat Commun. https://doi.org/10.1038/ncomms1171

41. Vismara C, Battista V, Vailati G, Bacchetta R (2000) Paraquat induced embryotoxicity on Xenopus laevis development. Aquat Toxicol. https://doi.org/10.1016/S0166-445X(99)00080-6

42. Hamm JT, Hinton DE (2000) The role of development and duration of exposure to the embryotoxicity of diazinon. Aquat Toxicol. https://doi.org/10.1016/S0166-445X(99)00065-X

43. Willey JB, Krone PH (2001) Effects of endosulfan and nonylphenol on the primordial germ cell population in pre-larval zebrafish embryos. Aquat Toxicol. https://doi.org/10.1016/S0166445X(00)00178-8

44. Aydin R, Köprücü K (2005) Acute toxicity of diazinon on the common carp (Cyprinus carpio L.) embryos and larvae. Pestic Biochem Physiol. https://doi.org/10.1016/j.pestbp.2005.03.001

45. González-Doncel M, De La Peña E, Barrueco C, Hinton DE (2003) Stage sensitivity of medaka (Oryzias latipes) eggs and embryos to permethrin. Aquat Toxicol. https://doi.org/10.1016/S0166445X(02)00090-5

46. Kienle C, Köhler HR, Gerhardt A (2009) Behavioural and developmental toxicity of chlorpyrifos and nickel chloride to zebrafish (Danio rerio) embryos and larvae. Ecotoxicol Environ Saf. https://doi.org/10.1016/j.ecoenv.2009.04.014

47. Slotkin TA (2004) Cholinergic systems in brain development and disruption by neurotoxicants: Nicotine, environmental tobacco smoke, organophosphates. Toxicol. Appl. Pharmacol 
48. Rihel J, Prober DA, Arvanites A et al (2010) Zebrafish behavioral profiling links drugs to biological targets and rest/wake regulation. Science 327:348-351. https://doi.org/10.1126/science.1183090

49. Sledge D, Yen J, Morton T et al (2011) Critical duration of exposure for developmental chlorpyrifosinduced neurobehavioral toxicity. Neurotoxicol Teratol. https://doi.org/10.1016/j.ntt.2011.06.005

50. Eddins D, Cerutti D, Williams $P$ et al (2010) Zebrafish provide a sensitive model of persisting neurobehavioral effects of developmental chlorpyrifos exposure: Comparison with nicotine and pilocarpine effects and relationship to dopamine deficits. Neurotoxicol Teratol. https://doi.org/10.1016/j.ntt.2009.02.005

51. Richendrfer H, Pelkowski SD, Colwill RM, Créton R (2012) Developmental sub-chronic exposure to chlorpyrifos reduces anxiety-related behavior in zebrafish larvae. Neurotoxicol Teratol. https://doi.org/10.1016/j.ntt.2012.04.010

52. Dishaw LV, Hunter DL, Padnos B et al (2014) Developmental exposure to organophosphate flame retardants elicits overt toxicity and alters behavior in early life stage zebrafish (danio rerio). Toxicol Sci. https://doi.org/10.1093/toxsci/kfu194

53. Crosby EB, Bailey JM, Oliveri AN, Levin ED (2015) Neurobehavioral impairments caused by developmental imidacloprid exposure in zebrafish. Neurotoxicol Teratol. https://doi.org/10.1016/j.ntt.2015.04.006

54. Slotkin TA, MacKillop EA, Rudder CL et al (2007) Permanent, sex-selective effects of prenatal or adolescent nicotine exposure, separately or sequentially, in rat brain regions: Indices of cholinergic and serotonergic synaptic function, cell signaling, and neural cell number and size at 6 months of age. Neuropsychopharmacology. https://doi.org/10.1038/sj.npp.1301231

55. Abercrombie ED, Keefe KA, DiFrischia DS, Zigmond MJ (1989) Differential Effect of Stress on In Vivo Dopamine Release in Striatum, Nucleus Accumbens, and Medial Frontal Cortex. J Neurochem. https://doi.org/10.1111/j.1471-4159.1989.tb09224.x

56. Araki KY, Fujimura S, MacDonald ME, Bhide PG (2006) Characterization of mouse striatal precursor cell lines expressing functional dopamine receptors. Dev Neurosci. https://doi.org/10.1159/000095114

57. Geyer MA (1995) Serotonergic functions in arousal and motor activity. Behav Brain Res. https://doi.org/10.1016/0166-4328(96)00065-4

58. Tufi S, Lamoree M, de Boer J, Leonards P (2015) Simultaneous analysis of multiple neurotransmitters by hydrophilic interaction liquid chromatography coupled to tandem mass spectrometry. J Chromatogr A. https://doi.org/10.1016/j.chroma.2015.03.056

59. Lu L, Zhan T, Ma M et al (2018) Thyroid Disruption by Bisphenol S Analogues via Thyroid Hormone Receptor $\beta$ : in Vitro, in Vivo, and Molecular Dynamics Simulation Study. Environ Sci Technol. https://doi.org/10.1021/acs.est.8b00776

60. Li Q, Zheng J, Xu S et al (2018) The neurotoxicity induced by PM2.5 might be strongly related to changes of the hippocampal tissue structure and neurotransmitter levels. Toxicol Res (Camb). https://doi.org/10.1039/c8tx00093j 
61. Li R, Zhang L, Shi Q et al (2018) A protective role of autophagy in TDCIPP-induced developmental neurotoxicity in zebrafish larvae. Aquat Toxicol. https://doi.org/10.1016/j.aquatox.2018.03.016

62. Tufi S, Leonards P, Lamoree M et al (2016) Changes in Neurotransmitter Profiles during Early Zebrafish (Danio rerio) Development and after Pesticide Exposure. Environ Sci Technol. https://doi.org/10.1021/acs.est.5b05665

63. Yamamoto K, Mirabeau O, Bureau C et al (2013) Evolution of dopamine receptor genes of the D1 class in vertebrates. Mol Biol Evol. https://doi.org/10.1093/molbev/mss268

64. Hatcher JM, Pennell KD, Miller GW (2008) Parkinson's disease and pesticides: a toxicological perspective. Trends Pharmacol. Sci

65. Jones DC, Miller GW (2008) The effects of environmental neurotoxicants on the dopaminergic system: A possible role in drug addiction. Biochem. Pharmacol

66. Bové J, Prou D, Perier C, Przedborski S (2005) Toxin-induced models of Parkinson's disease. NeuroRx. https://doi.org/10.1602/neurorx.2.3.484

67. Drechsel DA, Patel M (2008) Role of reactive oxygen species in the neurotoxicity of environmental agents implicated in Parkinson's disease. Free Radic. Biol. Med

68. Aldridge JE, Meyer A, Seidler FJ, Slotkin TA (2005) Alterations in central nervous system serotonergic and dopaminergic synaptic activity in adulthood after prenatal or neonatal chlorpyrifos exposure. Environ Health Perspect. https://doi.org/10.1289/ehp.7968

69. Chen XP, Wang X, Dong JY (2011) Different reaction patterns of dopamine content to prenatal exposure to chlorpyrifos in different periods. J Appl Toxicol. https://doi.org/10.1002/jat.1598

70. Sallinen V, Torkko V, Sundvik M et al (2009) MPTP and MPP + target specific aminergic cell populations in larval zebrafish. J Neurochem. https://doi.org/10.1111/j.1471-4159.2008.05793.x

71. Wang Y, Liu W, Yang J et al (2017) Parkinson's disease-like motor and non-motor symptoms in rotenone-treated zebrafish. Neurotoxicology. https://doi.org/10.1016/j.neuro.2016.11.006

72. McCormack AL, Thiruchelvam M, Manning-Bog AB et al (2002) Environmental risk factors and Parkinson's disease: Selective degeneration of nigral dopaminergic neurons caused by the herbicide paraquat. Neurobiol Dis. https://doi.org/10.1006/nbdi.2002.0507

73. Prasad K, Tarasewicz E, Mathew J et al (2009) Toxicokinetics and toxicodynamics of paraquat accumulation in mouse brain. Exp Neurol. https://doi.org/10.1016/j.expneurol.2008.11.003

74. Shepherd KR, Lee ESY, Schmued L et al (2006) The potentiating effects of 1-methyl-4-phenyl-1,2,3,6tetrahydropyridine (MPTP) on paraquat-induced neurochemical and behavioral changes in mice. Pharmacol Biochem Behav. https://doi.org/10.1016/j.pbb.2006.02.013

75. Litteljohn D, Mangano E, Shukla N, Hayley S (2009) Interferon-y deficiency modifies the motor and co-morbid behavioral pathology and neurochemical changes provoked by the pesticide paraquat. Neuroscience. https://doi.org/10.1016/j.neuroscience.2009.09.025

76. Nagatsu T, Levitt M, Udenfriend S (1964) The initial step in norepinephrine biosynthesis. In: Tyrosine Hydroxylase. J Biol Chem 
77. Chaube R, Joy KP (2002) Effects of altered photoperiod and temperature, serotonin-affecting drugs, and melatonin on brain tyrosine hydroxylase activity in female catfish, Heteropneustes fossilis: A study correlating ovarian activity changes. J Exp Zool. https://doi.org/10.1002/jez.10185

78. Pasqualini C, Leviel V, Guibert B et al (1991) Inhibitory Actions of Acute Estradiol Treatment on the Activity and Quantity of Tyrosine Hydroxylase in the Median Eminence of Ovariectomized Rats. J Neuroendocrinol. https://doi.org/10.1111/j.1365-2826.1991.tb00319.x

79. Weltzien FA, Pasqualini C, Sébert ME et al (2006) Androgen-dependent stimulation of brain dopaminergic systems in the female European eel (Anguilla anguilla). Endocrinology. https://doi.org/10.1210/en.2005-1477

80. Brooks Al, Chadwick CA, Gelbard HA et al (1999) Paraquat elicited neurobehavioral syndrome caused by dopaminergic neuron loss. Brain Res

81. Reeves R, Thiruchelvam M, Baggs RB, Cory-Slechta DA (2003) Interactions of Paraquat and Triadimefon: Behavioral and Neurochemical Effects. Neurotoxicology. https://doi.org/10.1016/S0161-813X(03)00057-3

82. Meyer A, Seidler FJ, Cousins MM, Slotkin TA (2003) Developmental neurotoxicity elicited by gestational exposure to chlorpyrifos: When is adenylyl cyclase a target? Environ Health Perspect. https://doi.org/10.1289/ehp.6468

83. Meyer A, Seidler FJ, Slotkin TA (2004) Developmental effects of chlorpyrifos extend beyond neurotoxicity: Critical periods for immediate and delayed-onset effects on cardiac and hepatic cell signaling. Environ Health Perspect

84. Adigun AA, Seidler FJ, Slotkin TA (2010) Disparate developmental neurotoxicants converge on the cyclic AMP signaling cascade, revealed by transcriptional profiles in vitro and in vivo. Brain Res. https://doi.org/10.1016/j.brainres.2009.12.025

85. Thompson TL, Moss RL (1994) Estrogen Regulation of Dopamine Release in the Nucleus Accumbens: Genomic-and Nongenomic-Mediated Effects. J Neurochem. https://doi.org/10.1046/j.1471-4159.1994.62051750.x

86. Zhang D, Kanthasamy A, Anantharam V, Kanthasamy A (2011) Effects of manganese on tyrosine hydroxylase $(\mathrm{TH})$ activity and TH-phosphorylation in a dopaminergic neural cell line. Toxicol Appl Pharmacol. https://doi.org/10.1016/j.taap.2010.03.023

87. Tobiansky DJ, Will RG, Lominac KD et al (2016) Estradiol in the Preoptic Area Regulates the Dopaminergic Response to Cocaine in the Nucleus Accumbens. Neuropsychopharmacology. https://doi.org/10.1038/npp.2015.360

88. Scott GR, Sloman KA (2004) The effects of environmental pollutants on complex fish behaviour: Integrating behavioural and physiological indicators of toxicity. Aquat. Toxicol

89. Tierney KB (2011) Behavioural assessments of neurotoxic effects and neurodegeneration in zebrafish. Biochim. Biophys. Acta - Mol. Basis Dis

\section{Figures}




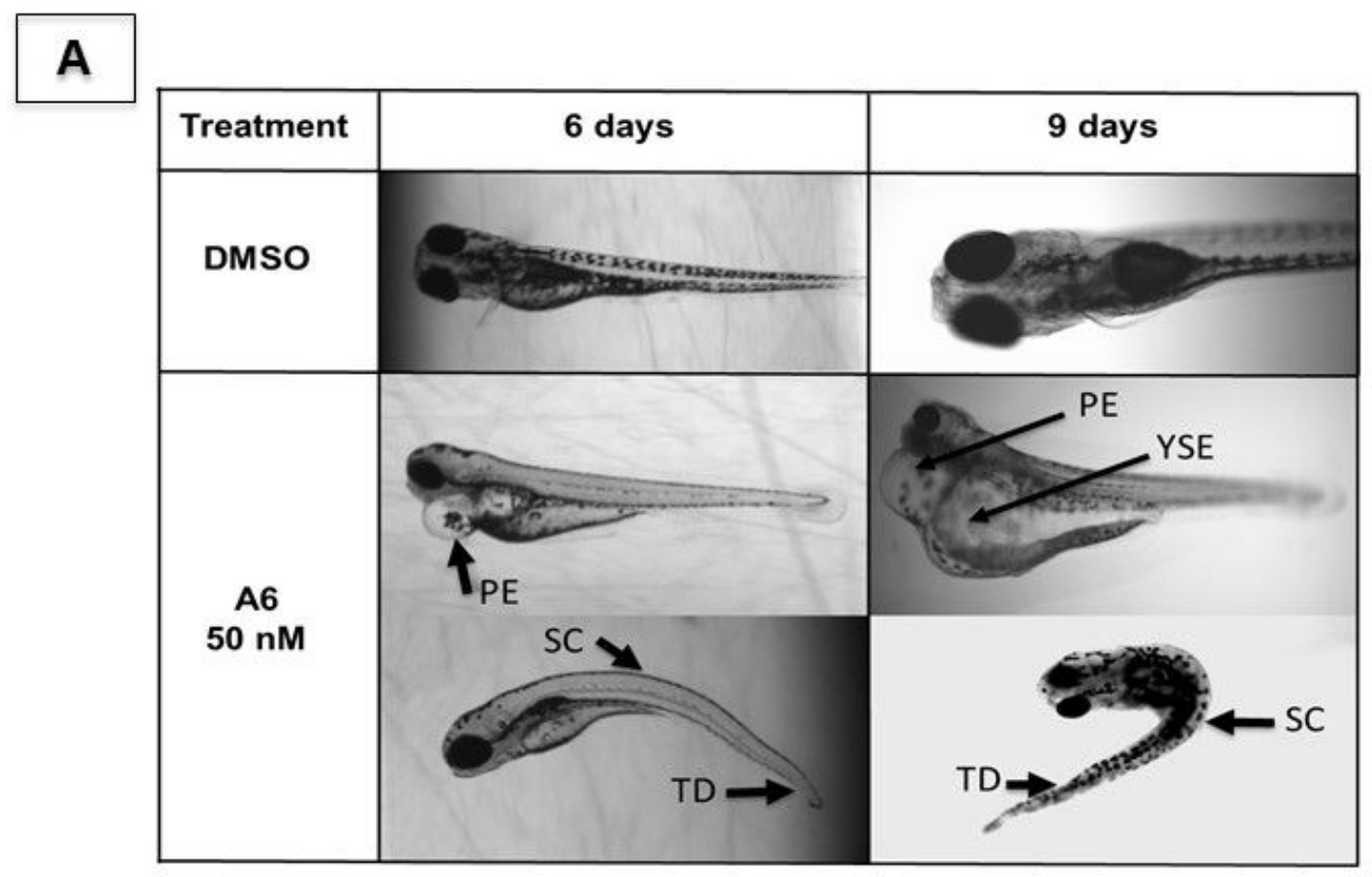

\section{B}

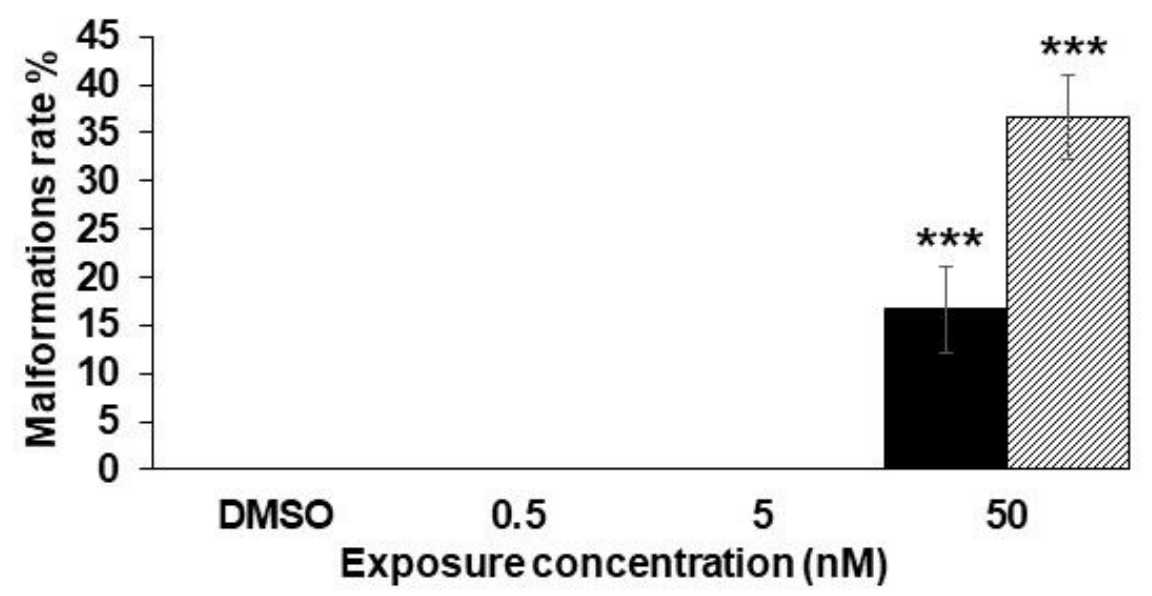

Figure 1

\section{Figure 1}

Effect of A6 on zebrafish morphology after 6 and 9 days of treatment. (A): PE, pericardial edema; YSE, yolk sac edema; SC: spinal curvature; TD, tail deformity. (B): Percentage malformation rate for all tested concentrations of A6. Asterisks indicate significantly differences from the control, symbols: ${ }^{*}=p<0.05$; $\star \star=0.05 \leq \mathrm{p}<0.001 ; * \star \star * 0.001 \leq \mathrm{p}<0.0001$. 

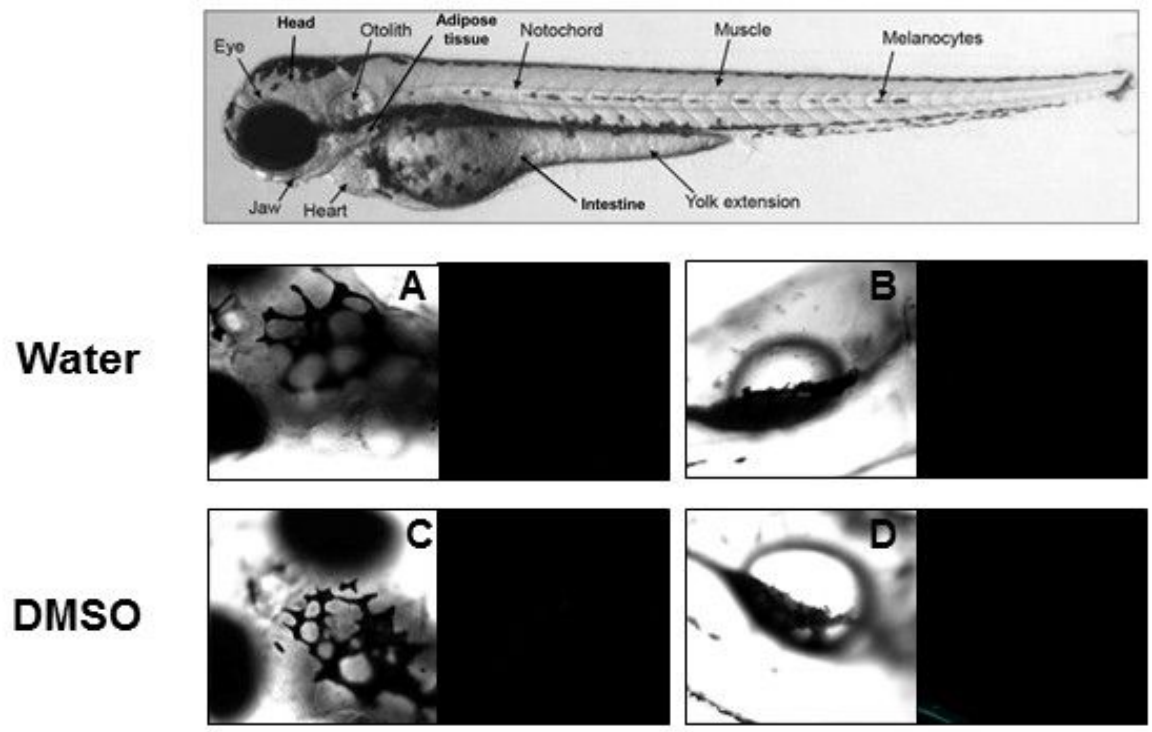

A6

$0.5 \mathrm{nM}$
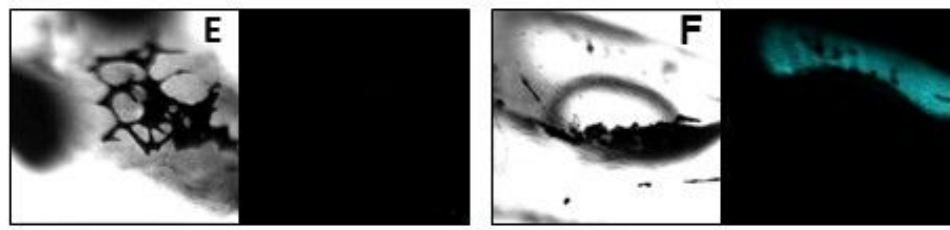

A6

$5 \mathrm{nM}$
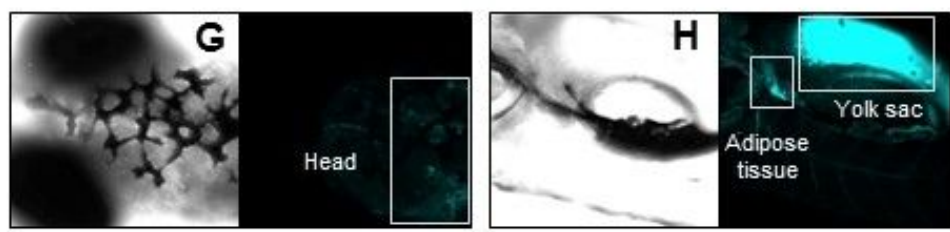

A6
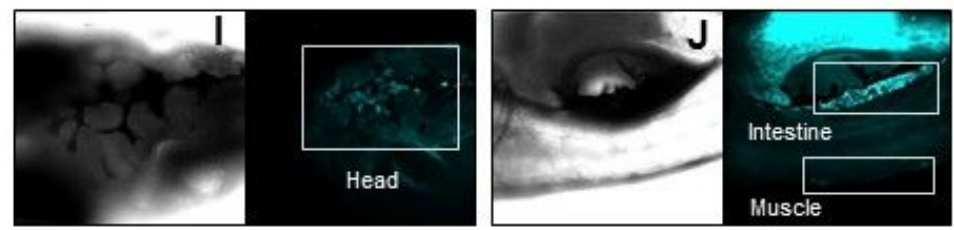

Figure 2

\section{Figure 2}

A6 accumulation in zebrafish tissue. (A, C, E, G, I) head with Bright field and Fluorescence of confocal microscopy; $(B, D, F, H, J)$ the rest of the body. Scale bars: $100 \mu \mathrm{m}$. Asterisks indicate significantly differences from the control, symbols: ${ }^{*}=p<0.05 ; * \star=0.05 \leq p<0.001 ; \star \star \star=0.001 \leq p<0.0001$. 


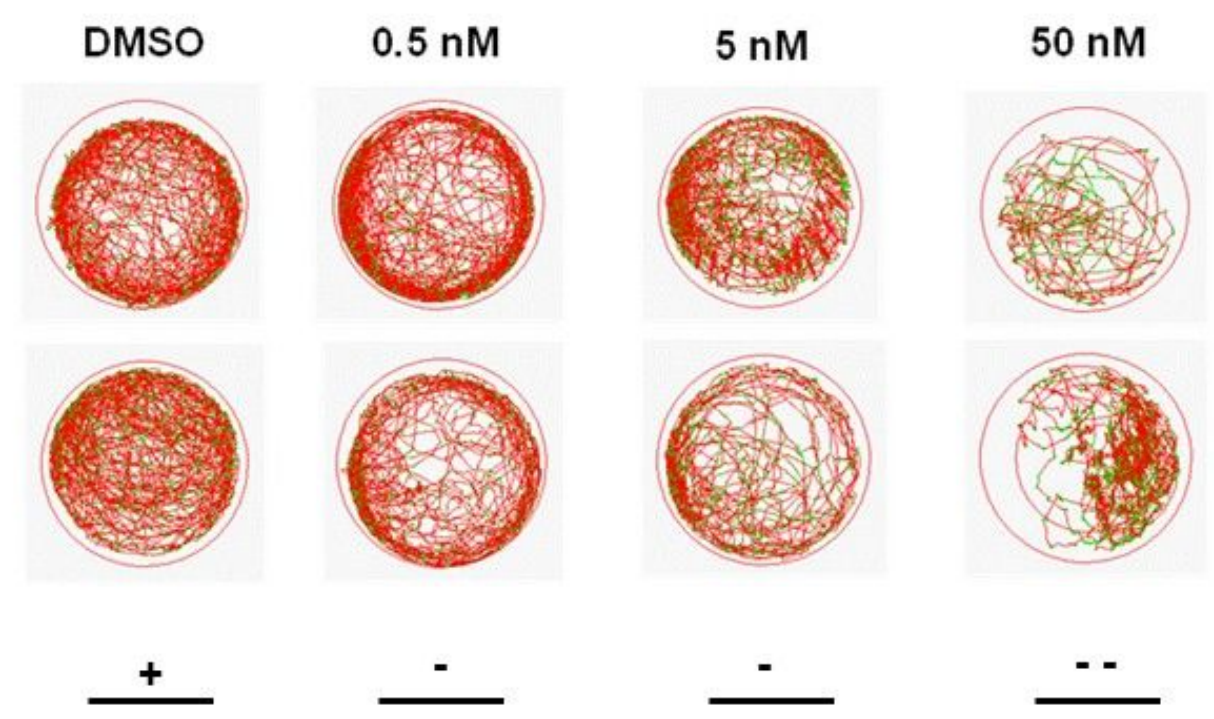

Duration of trips to the center (expressed in s)

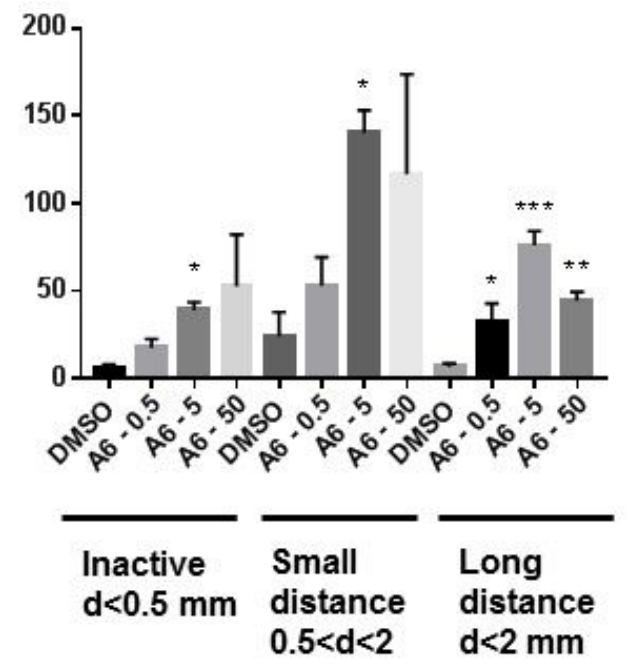

Duration of trips to the periphery (expressed in s)

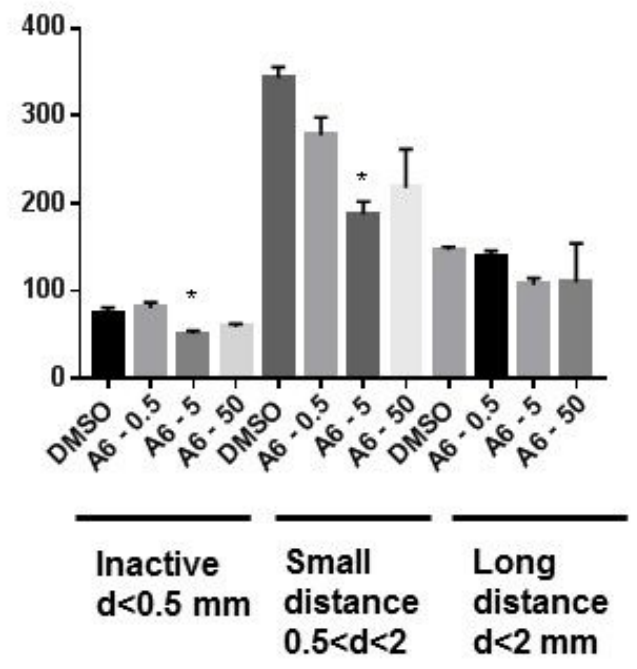

Figure 3

\section{Figure 3}

Effect of A6 on larval swimming behavior. Species are put individually in an observation chamber and their movements are continuously recorded over the next $10 \mathrm{~min}$. Figure shows four representative tracks from 20 larvae as well as the duration of trips to the center or to the periphery (expressed in s) after A6 exposure or to control (DMSO). The overall activity for each exposure group was represented by symbols: 
$+:$ active; $-:$ less active; $--:$ very less active. Asterisks indicate significantly differences from the control $(*=$ $p<0.05 ; * \star=0.05 \leq p<0.001 ; * \star *=0.001 \leq p<0.0001)$.
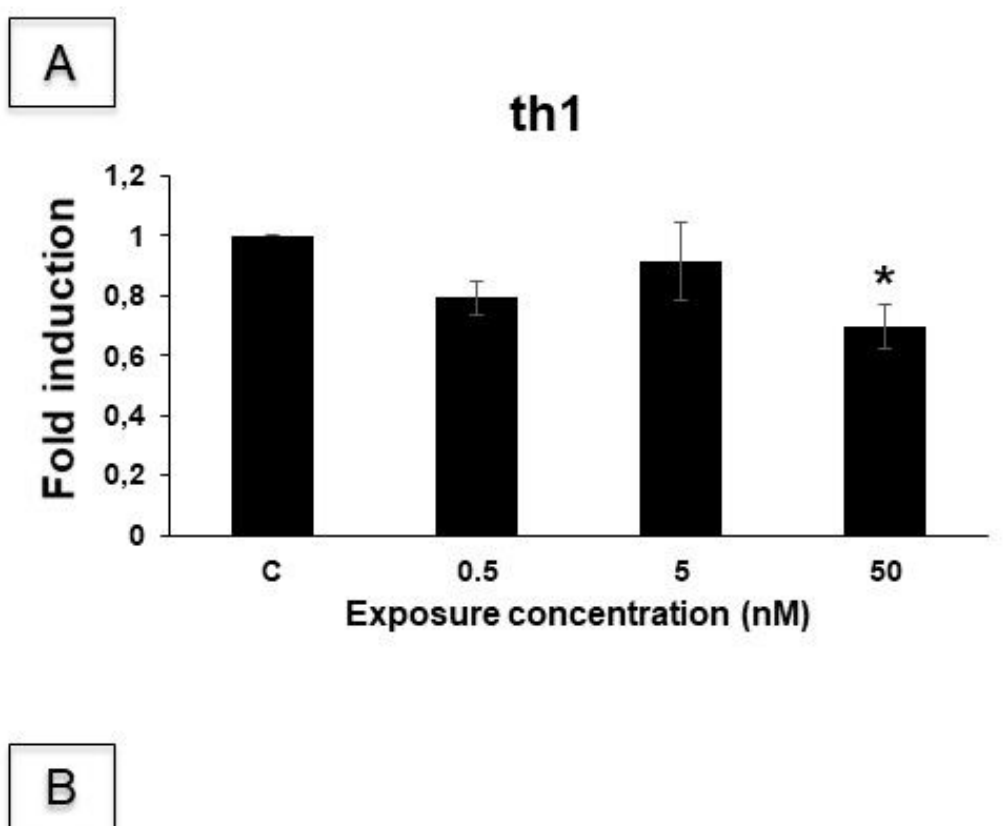

th2

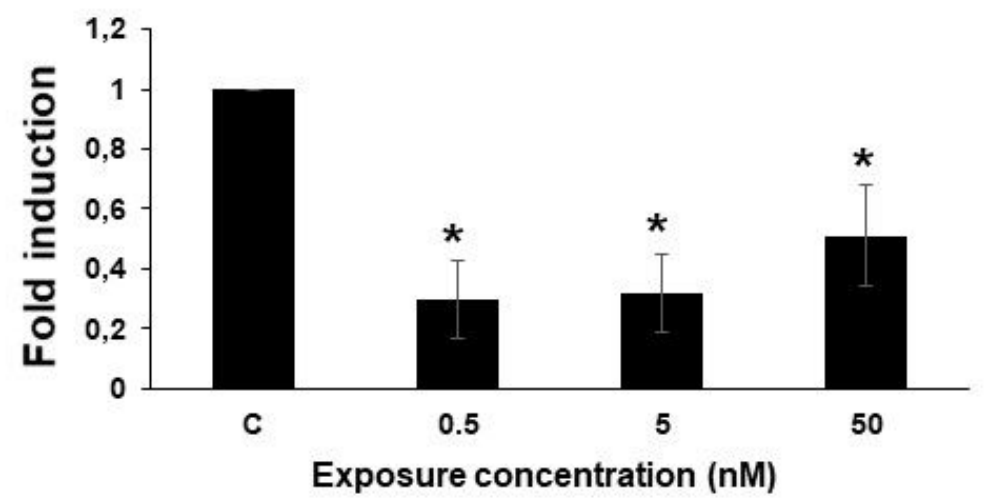

Figure 4

Figure 4

Relative gene expression of th1 and th2 after A6 exposure. Results are given as mean values \pm SEM ( $n=$ 9 replicates). Asterisks indicate significantly differences from the control, symbols: ${ }^{*}=p<0.05 ; \star \star ~=0.05$ $\leq \mathrm{p}<0.001 ; * \star \star * 0.001 \leq \mathrm{p}<0.0001$. 

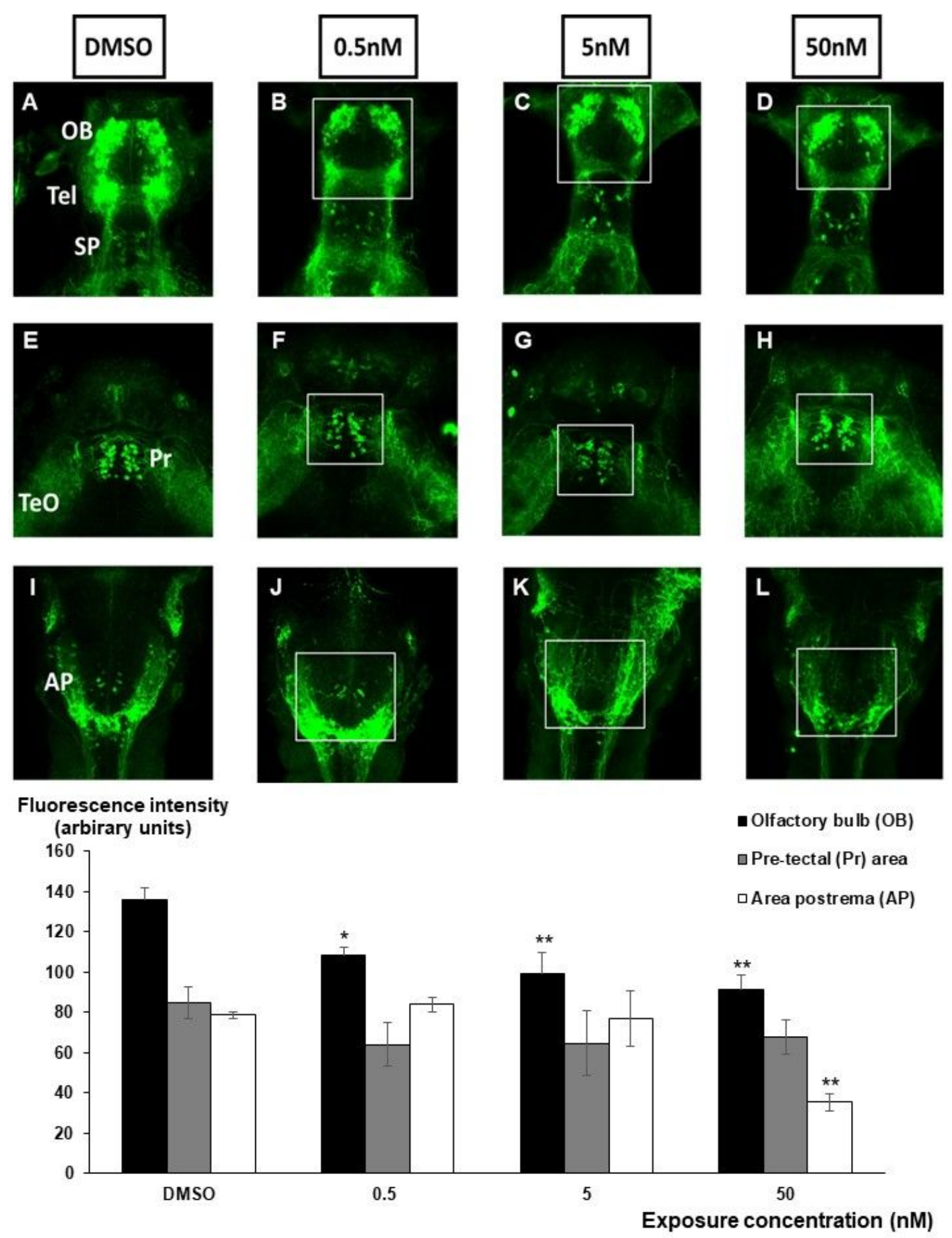

Figure 5

\section{Figure 5}

Tyrosine hydroxylase immunohistochemistry in wild type zebrafish larvae (6 dpf) exposed to A6. Olfactory bulb (OB), telencephalon (Tel), subpallium (SP), pretectum ( $\mathrm{Pr})$, optic tectum (TeO), area postrema (AP), Green staining is tyrosine hydroxylase-positive catecholaminergic cells. (A, E, I) represent a strong positive labeling of tyrosine hydroxylase in the forebrain in control animals. $(B, C, D),(F, G, H)$ and $(J, K, L)$ show the areas of immunostaining of tyrosine hydroxylase respectively in the telencephalon 
and the diencephalon (pretectum and postrema) in individuals treated with A6. These are dorsal views of $100 \mu \mathrm{m}$ sections of the brain.

\section{Supplementary Files}

This is a list of supplementary files associated with this preprint. Click to download.

- Graphicalabstract.jpg 